\title{
Radiological and toxicity risk exposures of oil based mud: health implication on drilling crew in Niger Delta.
}

Okoro EE1,

Ochonma C1,

Omeje Mㄴ,

Sanni SE트,

Emetere ME2,

Orodu KB1,

Igwilo KC논

Author information

Environmental Science and Pollution Research International, 17 Dec 2019, 27(5):5387-5397

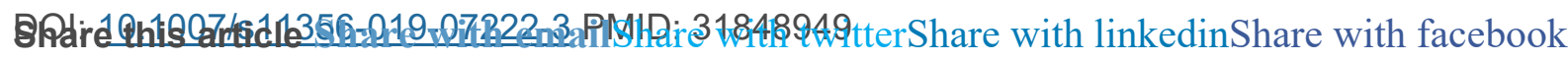

\section{Abstract}

Naturally occurring radioactive materials (NORMs) and the presence of toxic metals in drilling fluids/their additives have raised research interests in recent times owing to the risks associated with the exposure times for drillers of petroleum wells. In this study, two drilling fluids $A$ and $B$ were formulated, while two other Mud Samples $C$ and D were obtained from drilled shale and shale-sand formation zones. All four fluids were collected and analyzed for the presence of radioactive and heavy metals. Lead $(\mathrm{Pb})$, mercury $(\mathrm{Hg})$, cadmium $\mathrm{Cd})$, zinc $(\mathrm{Zn})$, chromium (Cr), aluminum (Al), arsenic (As), nickel (Ni), and copper (Cu) were detected in the mud samples. The heavy metal contents of the mud samples are in the following decreasing order of magnitude $\mathrm{Hg}>\mathrm{Pb}>\mathrm{Cd}>\mathrm{Cr}$. In Samples $\mathrm{A}-\mathrm{D}, \mathrm{Hg}, \mathrm{Pb}, \mathrm{Cr}$, and $\mathrm{Cd}$ were found to have significant concentrations, and the concentrations of these metals increased in the mud samples after they were used for drilling. The concentration of $\mathrm{Hg}$ was above the permissible limit. Also, the concentrations of $\mathrm{Pb}, \mathrm{Cu}, \mathrm{As}$, and $\mathrm{Al}$ found in 
Mud Samples A and B can cause skin irritations over long-term exposures, while Cd, $\mathrm{Hg}$, $\mathrm{Zn}$, and $\mathrm{Ni}$ present in the samples were within levels that can cause lung infections or immune breakdown when ingested over long periods. The quantities of $\mathrm{Cd}, \mathrm{Hg}$, and $\mathrm{Cu}$ detected in Mud Samples C and D can cause skin irritations over long-term exposures, while those of $\mathrm{As}, \mathrm{Zn}, \mathrm{Ni}$, and $\mathrm{Al}$ were seen to have the potential to cause dermal infections/diseases. Based on the results obtained, the cancer risk for the drilling crew lies within $1.1 \times 10^{-3}-7.7 \times 10^{-3} \mathrm{HQ}$. The highest dose rate, radium release, and external hazard index were obtained for Mud Sample $\mathrm{C}$ whose radium equivalent was judged to be far below the critical safe limit for the drillers. The radium equivalent activity for the two field mud samples ( $C$ and $D$ ) were estimated to be 27.467 and $22.978 \mathrm{~Bq} \mathrm{~kg}^{-1}$, respectively, which is the maximum activity obtained for the analyzed samples. The maximum radium equivalent activity for Mud Sample C was estimated as $27.48 \mathrm{~Bq} \mathrm{~kg}^{-1}$ with a corresponding external hazard index of 0.7 . Based on the analysis, there is a significant correlation between the concentration of heavy metals and the radionuclides found in the mud samples.

\section{Full text links}

\section{References}

\section{Citations \& impact}

\section{Similar Articles}

